\title{
1. The antique genetic plight of the Mediterranean monk seal (Monachus 3 monachus)
}

4
Jordi SALMONA ${ }^{1 *}$, Julia DAYON ${ }^{1,2}$, Emilie LECOMPTE ${ }^{1}$, Alexandros A. KARAMANLIDIS ${ }^{3}$, Alex AGUILAR ${ }^{4}$, Pablo FERNANDEZ DE LARRINOA ${ }^{5}$, Rosa PIRES ${ }^{6}$, Giulia $\mathrm{MO}^{7}$, Sabrina AGNESI ${ }^{7}$, Asunción BORRELL ${ }^{4}$, Erdem DANYER ${ }^{8,9}$, Bayram ÖZTÜRK ${ }^{8,10}$, Arda M. TONAY ${ }^{8,10}$, Luis M. GONZÁLEZ ${ }^{11}$, Panagiotis DENDRINOS ${ }^{3}$, Philippe GAUBERT ${ }^{*}$

1. Laboratoire Évolution \& Diversité Biologique, CNRS-UPS-IRD, Université Paul Sabatier, 118 route de Narbonne, 31062 Toulouse, France

2. CEFE, Univ Montpellier, CNRS, EPHE-PSL University, IRD, Montpellier, France

3. MOm/Hellenic Society for the Study and Protection of the Monk seal, Solomou Str. 18, 10682 Athens, Greece

4. Universitat de Barcelona, IRBio and Department of Evolutionary Biology, Ecology and Environmental Sciences, Faculty of Biology, Diagonal 643, 08028 Barcelona, Spain

5. Monk Seal Conservation Program, Fundación CBD-Habitat, Gustavo Fernández Balbuena 2, 28002 Madrid, Spain

6. Instituto das Florestas e Conservação da Natureza IP-RAM, Jardim Botânico da Madeira, Caminho do Meio, Bom Sucesso, 9064-512, Funchal, Madeira, Portugal

7. Istituto Superiore per la Protezione e la Ricerca Ambientale (ISPRA), Via Vitaliano Brancati 48, 00144, Rome, Italy

8. Turkish Marine Research Foundation (TUDAV), PO Box 10, Beykoz, Istanbul, Turkey

9. Veterinary Control Central Research Institute, Ankara, Turkey

10. Istanbul University, Faculty of Aquatic Sciences, Ordu Cad. No: 8 Laleli, Istanbul, Turkey

11. Subdirección General de Biodiversidad Terrestre y Marina, Ministerio para la Transición Ecológica y el Reto Demográfico, Pza. San Juan de la Cruz, 10. E-28071. Madrid, Spain

${ }^{*}$ Corresponding authors:

Jordi SALMONA: jordi.salmona@gmail.com

Philippe GAUBERT: philippe.gaubert@univ-tlse3.fr 


\section{Abstract}

34 Disentangling the impact of Late Quaternary climate change from human activities can have 35 crucial implications on the conservation of endangered species. We investigated the population genetics and demography of the Mediterranean monk seal (Monachus monachus), one of the world's most endangered marine mammals, through an unprecedented dataset encompassing historical (extinct) and extant populations from the eastern North Atlantic to the entire Mediterranean Basin. We show that Western-Sahara/Mauritania (Cabo Blanco), Madeira, Western Mediterranean (historical range) and Eastern Mediterranean regions segregate in four populations. This structure is likely the consequence of recent drift, combined with long-term isolation by distance $\left(R^{2}=0.7\right)$, resulting from prevailing short-distance $(<500 \mathrm{~km})$ and infrequent long-distance dispersal $(<1,500 \mathrm{~km})$. All populations (Madeira especially), show high levels of inbreeding and low levels of genetic diversity, seemingly declining since historical time, but surprisingly not being impacted by the 1997 massive die-off in Cabo Blanco. Approximate Bayesian Computation analyses support scenarios combining local extinctions and a major effective population size decline in all populations during Antiquity. Our results suggest that the early densification of human populations around the Mediterranean Basin coupled to the development of seafaring techniques were the main drivers of the decline of Mediterranean monk seals.

\section{Keywords}

54 Mediterranean monk seals, Population decline, Demographic history, Marine mammals, Genetic 55 diversity, Isolation by distance. 


\section{Background}

58 Because Late Quaternary extinctions were caused by the superimposed effects of climate change and human activities from the Last Glacial Maximum (LGM) onwards (ca. 25-10 ka; [1]), distinguishing between the respective impact of recent climate- and human-driven changes on the biosphere has proven challenging [2]. Differentiating climate- and human-driven impacts is similarly relevant to currently endangered species. Indeed, informed conservation planning relies on a systemic approach including knowledge of species' demographic history [3], which in turn can be used to predict species' ability to adapt to future climate changes $[4,5]$.

Pinnipeds are marine mammals that rely on coastal haul-out areas during their annual life cycle. As such, they have been affected by LGM climate changes and early human activities [6,7], although the impact of the latter (through targeted hunting) may be posterior to the end of the LGM in this case (but see [8]). Despite the fact that the Mediterranean monk seal (MMS; Monachus monachus) is arguably the world's most endangered pinniped [9], the factors responsible for its critical conservation status are not well understood. The MMS once ranged across the entire Temperate Northern Atlantic province [10], from the Black Sea and the Mediterranean Basin into North Atlantic eastern waters encompassing the coasts of western Africa, the Macaronesian islands and the northern Iberian Peninsula [11-13]. Nowadays, the species is fragmented into three isolated populations, including the eastern Mediterranean (ca. 187-240 mature individuals [14]) and the eastern North Atlantic, in Cabo Blanco (Western Sahara/Mauritania) (ca. 350 individuals) and the archipelago of Madeira (ca. 20 individuals; [15]) (Fig. 1).
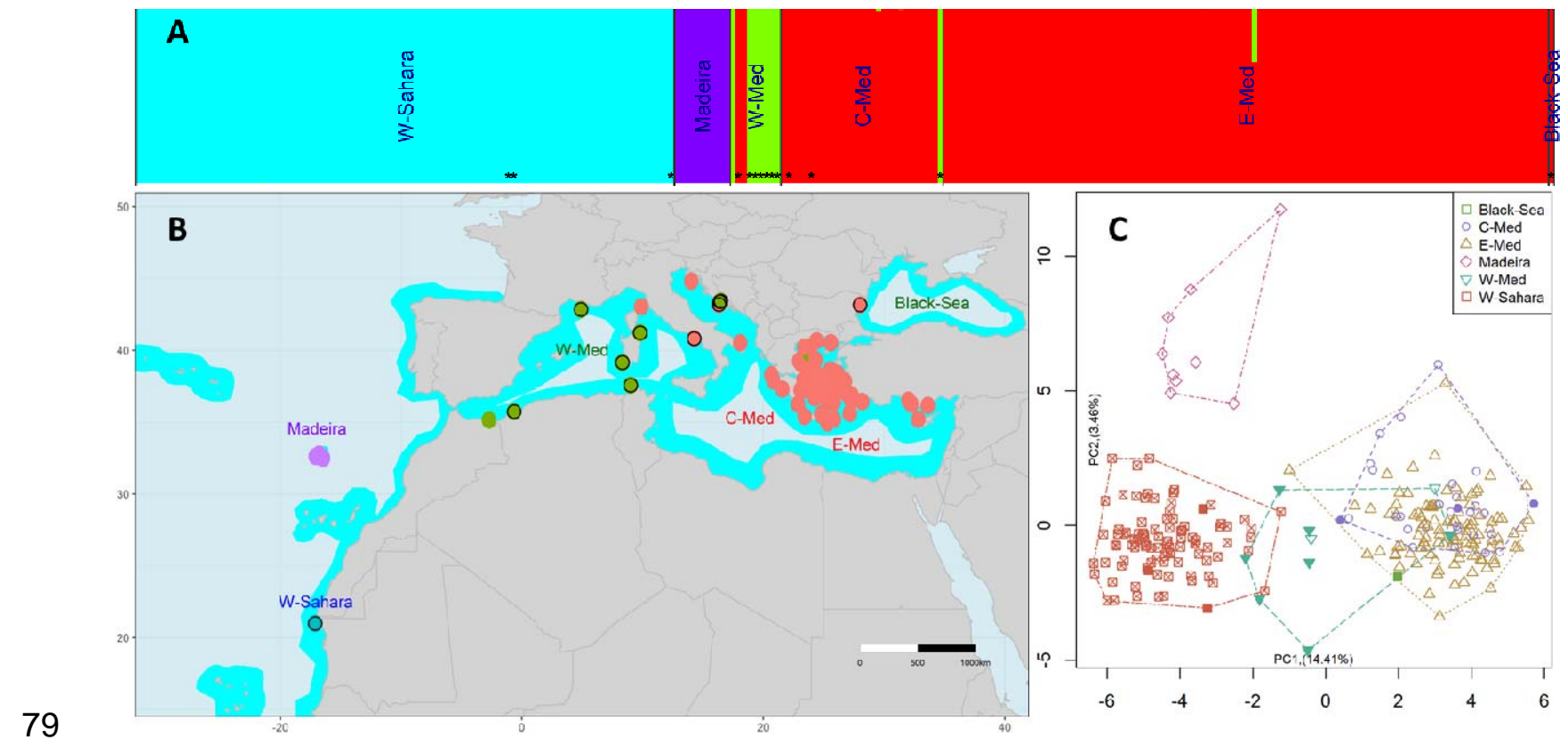
East cline of differentiation on the first axis. In $\mathbf{A}$, the samples are ordered by regions, sorted from West to East, separated by vertical black lines, and stars denote historical samples. In B, black circles denote locations that include historical samples and the cyan area represents the putative ancient MMS distribution. In C, full and empty symbols represent historical and modern samples respectively. W-Sahara: Western-Sahara/Mauritania, W-Med: western Mediterranean Sea, C-Med: central Mediterranean Sea, E-Med: eastern Mediterranean Sea.

A combination of extrinsic (human activities) and intrinsic (e.g., low genomic diversity, high susceptibility to diseases) factors has been proposed to explain the local extinctions affecting the species [16,17], and to a larger extent the extinction proneness observed in the entire Monachinae subfamily (which also includes the endangered Hawaiian monk seal Neomonachus schauinslandii and the extinct Caribbean monk seal $N$. tropicalis [18]). As an iconic representative of the Mediterranean Basin biodiversity hotspot [19], the MMS could have suffered from targeted hunting since the advent of the early Mediterranean sailors (Bronze Age; [20-22]). From the end of the Middle Age (XVth century), the massive exploitation of the species-notably in the Atlantic Ocean-became documented through the logbooks of European marine explorers [12,23]. Over the last centuries, MMS populations have been further impacted by the expansion of the fishing industry, deliberate killing by fishermen, marine pollution and human coastal encroachment, leading to local extinctions in most of the species' range, notably in the western Mediterranean and the Black Sea [13,24-26].

The decline of the MMS is documented from historical mass killing [11,20,27], local extinctions [28], massive die-off [29], and genetic inferences [30]. However, the respective impacts of Late Quaternary climatic fluctuations and anthropogenic pressures on the demographic history of the species remain poorly understood. Yet, the LGM induced significant changes in the Mediterranean Basin, such as lowering of sea level (down to $-120 \mathrm{~m}$; [31]) and sea surface temperatures, and local variations in salinity $[32,33]$. Moreover, the impacts of human activities on MMS populations may have applied at different periods across the species' range, with early exploitation since the Middle Paleolithic [21,34], followed by a gradual dispersal of seafaring civilizations from the eastern Mediterranean Basin (where habitat loss and overexploitation has been documented since ca. 10,000 yrs) towards the western Mediterranean Basin and North Atlantic Ocean $[31,35]$.

Preliminary genetic studies have revealed the genetic isolation of the three extant populations of MMS, the low levels of genetic diversity (since at least the mid-XIXth century) [36,37], the local extinction of mitochondrial DNA (mtDNA) haplotype in the western Mediterranean Basin [38,39], the demographic bottleneck in the Western Sahara/Mauritania population $[30,40]$, and the signature of past metapopulation dynamics across the species' range $[36,41]$. In this study, we investigate the genetic patterns and demographic history of the MMS through an unprecedented dataset, including historical individuals collected across the majority of the species' range and the three extant populations. We use microsatellite genotyping and mtDNA sequencing of $375 \mathrm{MMS}$ to assess the historical population structure and dynamics of the MMS across the Mediterranean Basin and Northern Atlantic Ocean. Specifically, we delineate past and present population structure and diversity, and assess whether such patterns are consistent with scenarios of local extinctions together with genetic drift and inbreeding in extant populations. We also confront the different historical drivers (LGM vs. human activities) potentially affecting the MMS population dynamics across the Mediterranean Basin and Northern Atlantic Ocean through complementary population genetic 
and modeling approaches based on demographic models, incorporating population structure and connectivity among populations through time. Based on our results, we formulate recommendations that might contribute to future evidence-based conservation strategies of the MMS.

\section{Methods}

\section{Laboratory procedures and genotyping}

We collected 383 samples from recent $(1989$ - 2020) and historical $(N=54 ; 1833$ - 1975) specimens of MMS covering the extant populations' and historical species' range (Figs 1, S1-3). The delineation between recent (from 1989 on) vs. historical (prior to 1975) is based on the extinction period of the last resident MMS groups from the western and parts of the central Mediterranean Sea during the 1970s [20], which suggested that after this period the fragmentation of the species' range into North Atlantic and eastern Mediterranean populations, as we know it today, was effective.

Genomic DNA was extracted from fresh tissue and skin samples, hairs, feces, bones and tanned skin using dedicated protocols (Method S1).

We amplified $524 \mathrm{bp}$ of the hypervariable region I of the mitochondrial control region (CR1) following [42] for the modern samples $(N=121)$, and a reconstructed 484 bp fragment encompassing all the variable sites of $\mathrm{CR} 1$ for the historical samples $(\mathrm{N}=3)$ as already described elsewhere [38] and detailed in method S2. We complemented our original dataset with 209 already published CR1 sequences [38,42]. Final CR1 alignment included 299 modern, 25 historical and four historical samples with unknown dating, for a total of 328 sequences (Figs 1, S1-3, Table S1-2).

We genotyped 383 samples at 19 nuclear microsatellites loci (nSSR [37], Method S3) from 329 modern samples and 54 historical samples. In order to mitigate scoring errors, PCRs of DNA extracts from hairs, faeces and museum material were replicated 2-to-5 times ([37], Method S3).

We controlled markers for linkage disequilibrium and departure from Hardy - Weinberg equilibrium (Method S3, Table S3; Fig. S4-7), and applied a two-fold sample selection procedure to optimize the number of individuals genotyped at informative loci. We relied on the minimum number of loci necessary to discriminate among individuals and the region-based DAPC contribution of loci (Method S3, Fig. S8). The final microsatellite data set comprised 253 samples (including 14 historical samples) with $10.18 \%$ missing data (Table S1, Figs 1 \& S1-2). In total, 204 samples (including 11 historical) were both sequenced for CR1 and genotyped at 19 loci.

\section{Genetic diversity and structure}

To assess the overall, per sampling site and per locus nSSR genetic diversity, we estimated allelic richness $\left(A_{R}[43]\right)$ using minimum sampling sizes of 5,10 and 25 for rarefaction with the R package hierfstat [44], the number of alleles $(A)$, the observed $\left(H_{0}\right)$ and Nei's 
unbiased expected heterozygosities $\left(H_{E}\right.$ [45]) with the R package adegenet [46]. To assess the effect of drift in the small colonies of MMS, we estimated the average individual inbreeding coefficient $F$ [46] in adegenet, from 100 iterations. We assessed the level of genetic differentiation among localities, populations, and time periods using Nei's $F_{\mathrm{ST}}$ [47]. Additionally, we investigated patterns of genetic variance with a principal component analysis (PCA) of allele frequencies, with a discriminant analysis of principal components (DAPC, considering sampling regions as groups), and through the SnapClust clustering approach [48]. To assess how the geographic distance alone explains the genetic diversity [49,50], we investigated individual- and population-based patterns of isolation by distance (IBD) using Mantel tests [51], with the genetic distance metric and the spatial scale that maximizes the amount of variance explained [52,53]. To assess how dispersal is distributed geographically we used Mantel correlograms [54,55].

For CR1, we estimated the number of haplotypes $(N h)$ and polymorphic sites (S), haplotype diversity ( $h[56]$ ), and nucleotide diversity ( $\pi$ [57]) per sampling area using the $R$ package pegas [58]. CR1 haplotype relationships were reconstructed with a maximum parsimony network using pegas. All above-mentioned methods are detailed in Method S4.

\section{Demographic history}

We used Approximate Bayesian Computation (ABC; [59]) to compare data simulated under several alternative scenarios to the real data (SSR \& CR1), and estimate parameters of interest from the best supported scenario [60-62]. We first tested scenarios assuming a single panmictic population and different histories of population size change (Figs S9-10). Second, we modeled stable-size structured populations with constant migration rates among populations (Figs S9, S11). These models included unsampled ghost populations mimicking extinct populations and a change in connectivity, mimicking the loss of gene flow among extant populations (Figs S9, S11, S12). Third, we combined population size change, structure, ghost populations, and changes in connectivity, to model populations that suffered one or several events of decline and fragmentation (Figs S9, S13). Structured scenarios also compared nisland, stepping-stone and spatially-explicit models of connectivity (Table S4, S5). Further details are described in Method S6.

\section{Results}

\section{Genetic diversity and structure}

The microsatellite population-structure analyses exhibited at K=2 (Figs 1 \& S14-15) a strong East-West pattern of differentiation $\left(F_{\mathrm{ST}}>0.4\right.$, Table S6-7) separating the Atlantic and Mediterranean populations. This pattern appeared as a continuous cline of differentiation driving the first component of the PCA (Fig. 1), and was also the first revealed by the DAPC representation (Fig. S16). Second, our analyses showed a clear segregation of Madeira from Western-Saharan/Mauritania individuals, clearly distinguishing the two North-Atlantic populations (Figs 1, S15-16). The Western-Mediterranean population formed a group relatively distinct from the Eastern-Mediterranean, and genetically intermediary between Central-Eastern 
Mediterranean and Atlantic populations (Figs 1, S15-16). The only historical sample genotyped from the Black Sea was assigned to the eastern Mediterranean population (Figs 1, S15). Further subdivision of the MMS resulted in erratic clustering results (Figs S14-15, S17).

Overall, all the populations showed relatively low nuclear genetic diversity $\left(H_{0}=0.12\right.$ $0.42 \& H_{E}=0.04-0.36$ ) and a wide range of inbreeding levels (Fig. 2). Madeira had the lowest levels of genetic diversity across all estimated indexes and among the highest estimates of inbreeding (Fig. 2, Tables S6-7). The historical Western-Mediterranean population showed a relatively high allelic richness, and the Western-Sahara/Mauritania and Eastern-Mediterranean populations exhibited the highest number of private alleles (Fig. 2). The historical sample from the Black Sea did not harbor private alleles (Fig 2). Similarly, mtDNA (CR1) diversity was low in all populations, with Madeira exhibiting only one haplotype (Table S2, Fig S18).

\section{Figure 2. Monachus monachus nuclear genetic diversity.}

Boxplot of the SSR $(\mathbf{A})$ allelic richness $\left(A_{R}\right),(\mathbf{B})$ observed $\left(H_{0}\right)$, and $(\mathbf{C})$ expected $\left(H_{E}\right)$ heterozygosity, (D) mean private alleles $\left(P_{\mathrm{A}}\right)$ of 500 resamplings of the smallest sample size across each population, and barplot of the number of private alleles $\left(P_{\mathrm{A}}\right)$, and $(\mathrm{E})$ boxplot of the average individual inbreeding coefficient $(F)$, per population, expressed for modern (>1979) and historical $(<1980)$ samples. In A-D, historic samples were removed from the analyses for all extant populations apart from the W-Med where no population is clearly identified and for which we almost exclusively have historic samples. Letters and box-colors in A-D illustrate the Tukey post-hoc group assignment. W-Sahara: Western-Sahara/Mauritania, W-Med: Western Mediterranean Sea, CE-Med: Central and Eastern Mediterranean Sea, C-Med: Central Mediterranean Sea, E-Med: Eastern Mediterranean Sea.

The likelihood estimates of individual homozygosity $(F)$ suggested higher levels of inbreeding in modern samples than in historical ones (per population; Fig. 2). In addition, the allelic richness $\left(A_{\mathrm{R}}\right)$ and the private allelic richness $\left(P_{\mathrm{A}}\right)$ were higher historically than in modern samples (Fig. S19). However, the overall observed $\left(H_{0}\right)$, and expected $\left(H_{\mathrm{E}}\right)$ heterozygosity, as well as the overall evolution of inbreeding levels through time (Fig. S19), did not exhibit a pattern of diversity loss across the timespan covered by our dataset (1840-2020). Across modern samples (>1975), and for the two major populations (Western-Sahara/Mauritania and Eastern-Mediterranean), we could not see any clear pattern of diversity loss between 1990 and 2020 (Figs S20-21). At the mtDNA level, one historical CR1 haplotype was not recovered in modern samples (MM07) and, reciprocally, one modern haplotype was not recovered from historical samples (MM06; Figs S18, S22-23). 
The investigation of the 1997 massive die-off of the Cabo Blanco (Western Sahara/Mauritania) colony shows that no population and individual-based genetic diversity indexes $\left(A_{\mathrm{R}}, H_{\mathrm{O}}, H_{\mathrm{E}}, F\right)$, apart from private alleles $\left(P_{\mathrm{A}}\right)$, were consistent with the genetic diversity decrease expected after a bottleneck despite a large sampling before and after the event has taken place (Figs S24-25). Furthermore, we did not record a clear signal of rare allele loss, or decrease in frequency, nor of major allele gain in frequency (Fig. S26-27), that are to be expected after a reduction of the population size [63,64].

In line with the PCA showing an East-West cline of differentiation, we found an isolation by distance (IBD) pattern explaining up to $69.6 \%$ of the among-individuals genetic distance variability (Figs 3, S28-29). Such a strong IBD signal was sustained by Mantel correlograms exhibiting high values for the first $500 \mathrm{~km}$ classes, progressively declining up to $\sim 1,500 \mathrm{~km}$, above which values were no longer significant or negative (Fig. 3). Females exhibited significant positive values up to higher distance classes $(1500 \mathrm{~km})$ than males $(700 \mathrm{~km})$, but this signal may have resulted from sample size differences among males and females for each class.

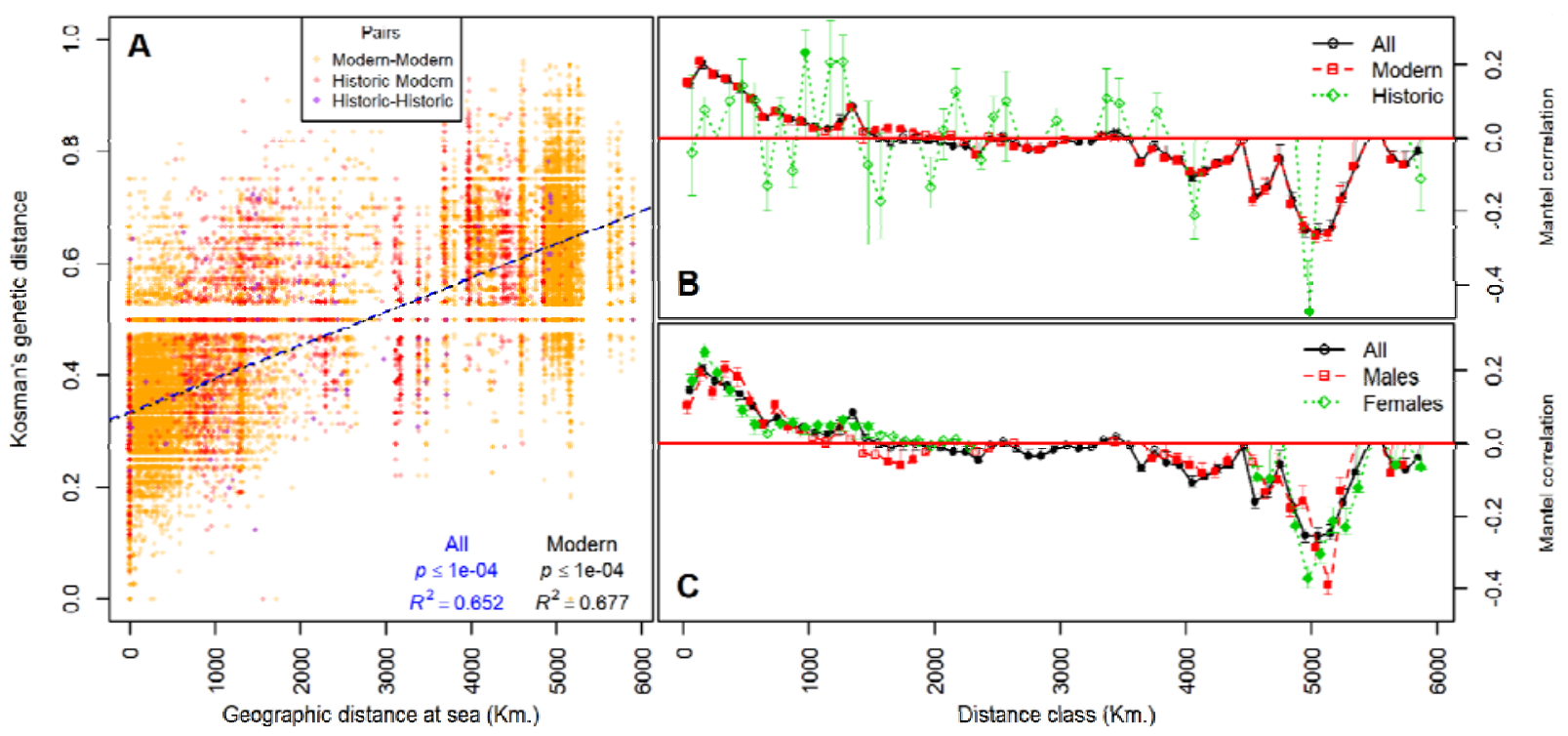

Figure 3. Isolation by distance in Monachus monachus.

A: isolation by distance (IBD) relationship between individual based genetic and maritime distances. B \& C: Mantel correlogram of spatial correlation, for 59 classes of $100 \mathrm{Km}$, in all, modern, and historic samples (B), and all, males and females samples (C). Significant values, over 1000 permutations, are represented by filled symbols. Complementary analyses using alternative genetic distances are presented in Figs S26-27.

\section{Demographic history}

The ABC procedure supported models including population structure, ghost populations (local extinctions) and an effective population size decline (Figs. S9-13). The most supported population structure used a custom stepping stone framework, realistically modeling extant and extinct population connectivity, based on their respective position in space (Table S4, S8-9, \& Figs S12-13). Among the models including these features, the most supported ones (M180 \& M181) suggest that all sampled populations underwent one to two major declines, most of which 
were of at least one order of magnitude (Table S10, Figs 4, S30). Furthermore, it reveals that these declines, and the loss of connectivity among sampled populations, most likely occurred during Antiquity (M181 \& M180, Table S10, Figs 4, S30-31), as well as at the onset of the Middle-Age (M180).

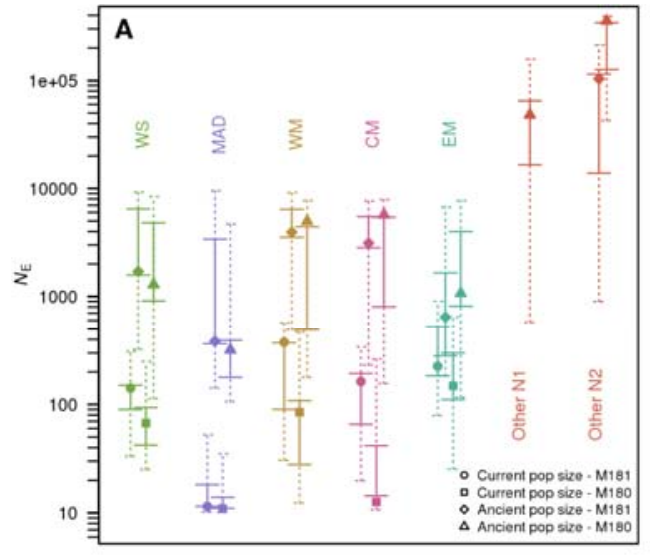

Sampled Regions

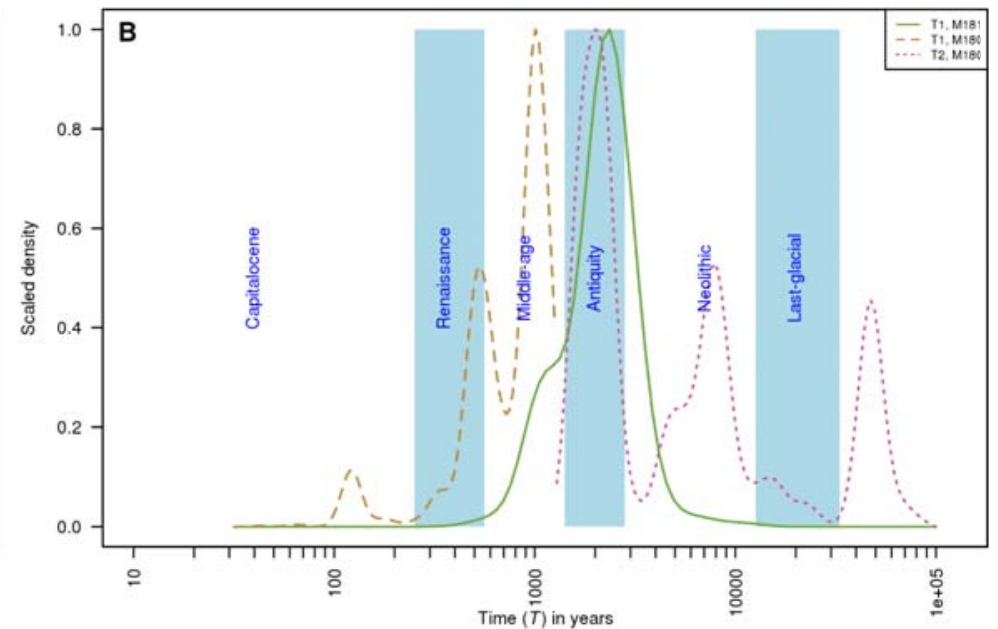

Figure 4. The antique decline of MMS.

ABC-GLM posterior estimates of effective population size $\left(N_{e} ; \mathbf{A}\right)$ and of the time $\left(T_{1} ; \mathbf{B}\right)$ of the major demographic event(s) -Population decline + local extinction + change in connectivity - estimated from the most likely scenarios (M181 \& M180), within the ABC framework. A: mode (symbol), $50 \%$ (continuous) and $95 \%$ (dotted) quantiles of the effective population size $\left(N_{e}\right)$ under the models 181 and 180 , represented after $\left(N_{0}\right.$ : current population) and before $\left(N_{1}\right.$ : ancient population) the demographic events occurring at $T_{1}$ and at $T_{2}$. B: scaled-density distributions of the time of the demographic event(s) $T_{1}$ and at $T_{2}$. WS: Western-Sahara/Mauritania, MAD: Madeira, WM: WesternMediterranean, CM: Central Mediterranean, EM: Eastern-Mediterranean.

\section{Discussion}

\section{The genetic structure of Mediterranean monk seals through time and space}

Our study is based on an unprecedented genetic sampling, covering the entire distribution range of the Mediterranean monk seal and encompassing historical (extinct) and extant populations. This enabled us to provide the most comprehensive diversity and structure assessment of the species to date in comparison to previous studies limited in their geographic and temporal representation and/or using meager genetic information. Our results illustrate how the inclusion of historical samples helps understanding the dynamics of species' genetic diversity through time and space [65]. The global analysis showed that MMS are composed of four populations, including the previously delineated eastern Mediterranean (reaching the Ligurian Sea as its westernmost location) and two northern Atlantic populations (Madeira and Western Sahara/Mauritania) [36-39,42], and a newly identified, historical population in the Western Mediterranean. The latter ranged from the northern Maghreb to southern France, Sardinia Isl. and the Adriatic Sea, partly overlapping at its eastern fringe with the extant eastern 
Mediterranean population (Fig. 1). Because the western Mediterranean population holds both North Atlantic and Mediterranean mitochondrial haplotypes, it could not be clearly delineated in the previous, single-locus studies integrating historical samples [38,39]. The modern sample from northern Morocco (1993) upsurges the long-standing question as to whether the western Mediterranean population still exists today, notably on the western Algerian coast where MMS were present until the recent past [66]. Although sightings of MMS across the western Mediterranean basin have been reported within the last c. $20 \mathrm{yrs}$ [67], their actual relevance is difficult to assess unless proper monitoring of potential breeding sites are systematized.

The status of the extinct population in the Black Sea [68] remains unsolved. The sole successfully-genotyped historical sample included in the SSR analyses did however carry information attributing it to the eastern Mediterranean population (Figs 1, S15). Together with the sharing of a unique CR1 haplotype in the Black Sea with individuals from the Aegean Sea, our preliminary results do not support the straits of Çanakkale (Dardanelles) and Istanbul (Bosphorus) as a putative barrier to MMS movements, despite its effect on other species at a wide taxonomic scale, including marine mammals $[69,70]$.

Although substantial differentiation was previously reported between Western Sahara/Mauritania and Madeira [37], Western Sahara/Mauritania and Eastern Mediterranean [36], and Aegean and lonian seas [41], our results demonstrate that this differentiation is clinal and likely a consequence of isolation by distance $\left(R^{2}=0.7\right.$, Figs 1,3$)$. At the level of the Mediterranean basin, similar continuous differentiation is found in several marine organisms with varying mobility [e.g. dolphins, Sea star [71,72]], suggesting that oceanic distance alone can affect species across a broad taxonomic range. Because the inclusion of historical samples did not disrupt the genetic covariation with geography, the isolation by distance pattern might have been long-standing over the past two centuries. Interestingly, this pattern, previously unveiled at the eastern Mediterranean Sea scale [41], appears driven by prevailing short distance $(<500 \mathrm{~km})$ and infrequent long distance dispersal $(<1,500 \mathrm{~km}$, Fig. 3). MMS may tend to establish in close proximity to their place of birth, eventually dispersing within their local water basin, and, on rare occasions, to further-away places. This is in sharp contrast with the lack of structure of Neomonachus schauinslandi, the Hawaiian Monk Seal [73], which shows long distance dispersal across a $\sim 2,700 \mathrm{~km}$ linear oceanic distribution likely facilitated by the strong oceanic surface currents active in that region [74]. On the contrary, our results suggest that the weaker and circular Mediterranean Sea currents, together with natal philopatry exacerbated by the rarity of breeding sites, remain likely contributors to the current MMS genetic structure.

\section{A long depauperate and decreasing genetic diversity}

Combining data from all extant populations, our genetic survey confirms that MMS harbors the most depauperate genetic diversity $\left(H_{\mathrm{E}}=0.04-0.36\right)$ of all seal species [30]. Furthermore, it reveals Madeira's dramatic levels of genetic diversity $\left(H_{E}=0.04\right.$, Fig. 2), which echoes its decline to less than 10 individuals in the 1980s [27]. As a matter of comparison, Madeira's diversity is lower than that of the ringed seal population (Pusa hispida) landlocked since the LGM in Saimaa Lake, Finland [75].

We uncovered a decrease of allelic richness $\left(A_{R}\right)$ and private allelic richness $\left(P_{\mathrm{A}}\right)$ from historical to modern samples, and an increasing trend in inbreeding at the population level (Figs 2, S19). This pattern is consistent with the trend exhibited by CR1 [38] and mitogenome [39] 
studies, confirming that MMS genetic diversity has decreased over the past two centuries. In all cases, the decrease in genetic diversity started from remarkably low historical levels, which could explain the relatively stable distribution of heterozygosity that we observed over time (Fig. S19). This contrasts with the sharp drop in diversity caused by commercial exploitation in other seal species [76,77], implying an older exploitation of MMS populations.

Remarkably, the MMS genetic diversity has not been decreasing in the past 30 years (Figs S20-21), at least in the two populations with sufficient temporal sampling (eastern Mediterranean and Cabo Blanco). This encouraging signal can be interpreted as the incipient results of conservation efforts and population recovery over that period [13]. However, this pattern is surprising in the Western Sahara/Mauritania, where we could not trace any substantial genetic diversity or minor allele frequency drop -except private allele loss- following the massive 1997 die-off that decimated more than two thirds of the Cabo-Blanco colony (Figs S24-25 [29]). The originally low diversity and high inbreeding in the population, a higher death rate of most inbred individuals at the time of the die-off, or an insufficient resolution of the studied loci, may have blurred declining pattern signatures. Additionally, individuals from unsurveyed nearby localities (e.g. Guerguerat) at the time of the mass die-off may have participated in maintaining the genetic diversity of the Cabo-Blanco colony (pers. obs. AA).

\section{Human-seal interactions in the Mediterranean basin: a history of overexploitation}

The low diversity and high levels of inbreeding in all MMS populations (Fig. 2) are strong signals for the species undergoing a major decline with limited gene flow among populations. Furthermore, the marked IBD pattern (Fig. 3) reveals that MMS populations were connected by gene flow in the recent past. These patterns are confirmed by our demographic modeling analyses, which suggest that populations were organized in a stepping-stone manner, connected by intermediary (extinct) populations. These populations underwent one to two major demographic declines during Antiquity, most of which were at least of one order of magnitude (Figs 4, S30).

Surprisingly, the LGM ( 20 ka ago) that dramatically affected the sea level $(\sim 120-130 \mathrm{~m}$ below current level) and the Mediterranean basin area, did not leave an identifiable signature in the MMS genetic data. The Neolithic transition allowed rapid human population growth and the development of complex civilizations [31,78], mastering increasingly sophisticated seafaring and fishing techniques $[79,80]$. By the rise of Antiquity, large human populations had spread across the entire Mediterranean basin and its islands [80-82]. Although the extent of hunting pressure on MMS is hard to accurately gauge at this time, historical sources relate hunting, meat consumption, oil use in lamps and skin use [83], conflict with fishermen [84], use in circus shows [85] and use of body parts to produce medicines [83]. In Antiquity, the species was reported to be common, widespread, and of 'naive' behavior towards humans, with rookeries of large size, and using open environments such as beaches, outcrops or promontories [83,86,87]. Such descriptions echoes the large ancient effective population sizes (between 100,000 and 356,000 individuals, Table S10) inferred from our demographic reconstructions, and is consistent with the ancestral population size estimates of Neomonachus tropicalis [88]. However, it is in sharp 
contrast with the current elusive nature of the species, its habits of resting and giving birth in caves and remote islets, all which are probably a result of long lasting persecution [9].

Whether Romans, as previously posited [11], and/or other ancient civilizations played a significant role in the abrupt demographic decline of MMS remains unsolved, given the lack of direct evidence. However, the Romans' Empire large scale wildlife exploitation that lead to localfish stock depletion and local megafauna extinction $[85,89,90]$, and the emerging evidence of their whaling activities [91] are clues pointing towards their potential role in the demise of MMS. Importantly, humans have been hunting MMS long before Antiquity [21,34,92,93] and have continued afterward [12], together with increasing competition for habitat use and marine resources. Wherefore, the MMS decline was likely a continuous process, with a peak during Antiquity that dramatically sealed the genetic depauperation of the species. Furthermore, sealed animals were undoubtedly processed on the beach, and this explains that only very few bones reached inland sites [93]. Thus, systematic sealing (alike whaling [91]) is unlikely to have produced large archeological accumulations, as is the case for smaller marine resources, like tuna [94]. The resulting paucity of ancient MMS remains [92,93] limit our ability to accurately conclude on a precise period of MMS overexploitation.

\section{Conservation outcomes}

The existence of a western Mediterranean MMS population, likely on the verge of extinction, calls for the urgent identification and protection of breeding areas. Prior sightings suggest that several sites potentially hosting individuals belonging to this population should be surveyed, monitored and adequately protected on priority (e.g. from Al Hoceima to Cap des Trois Fourches - Morocco, Balearic Islands - Spain, Corsica -France, Sardinia, Tuscan Archipelago, Sicily - Italy, , La Galite - Tunisia $[67,95])$.

The clinal pattern of genetic diversity across the entire species distribution supports the absence of locally manageable conservation units. It therefore calls for an ambitious integrative conservation plan that comprehensively includes all countries (30) of the MMS past distribution range. Such concerted actions should be strengthened by governmental and intergovernmental agencies efforts and policies [96].

The low genetic diversity of extant populations calls for the development of an ambitious program that includes (i) increasing the size of colonies and populations and (ii) restoring genetic diversity and connectivity among extant populations. Ensuring population growth should be at the core of the MMS conservation program, as it will directly improve the resilience of populations to stochastic events [29]. Ways of re-establishing dispersion among populations should be considered, through, for example, the conservation of historical breeding sites (see [67]).

However, the dramatic levels of genetic diversity reported from our study indicate that rescuing the genetic diversity of MMS through the translocation of individuals among extant populations $[97,98]$ is a scientifically-backed option to promote the long-term recovery of the species and should not be disregarded. Translocation should balance the benefits of counteracting the present limited gene flow among populations with any potential detrimental effects, such as the introduction into the receiving MMS community of parasites or disease to which it had not been previously exposed. 
Furthermore, our results demonstrate that all extant MMS populations were connected until recently, and that their differentiation is explained by their frequent short distance and rare long distance dispersal $(<1,500 \mathrm{~km})$. Theory predicts that gene flow reduces local adaptation [99], and small populations governed by strong genetic drift (e.g. Madeira) are less likely to have fine-scale local adaptations [100]. Therefore, translocation among inbred nearby populations presents limited risks of outbreeding depression [101,102]. The success of such genetic rescue is however conditioned by long-term conservation of extant populations, their habitat and resources, and actions to re-establishing natural dispersion among populations [102].

Finally, our broad scale genetic survey provides a new turnkey cost-efficient tool to accurately trace the origin of vagrant MMS individuals and monitor the genetic diversity of MMS populations and colonies. The combination of the 19 MMS microsatellites markers with the CR1 mitochondrial sequence may indeed serve not only to select the MMS individuals for potential translocation, but also to assess translocation success over time [98].

Data accessibility

\section{Acknowledgments}

438 We thank all the collectors and museums listed in Table S1 for providing access to genetic samples. We are grateful to Sophie Courjal and the staff of the "Plateau technique - Biologie moléculaire et microbiologie" at EDB for their assistance during lab work. This work was funded by the Fondation Prince Albert II de Monaco (project "Génétique de la conservation du phoque moine de Méditerranée"). The Genotoul bioinformatics (Bioinfo Genotoul) platforms provided computing resources, and the LABEX TULIP (ANR-10-LABX-0041) contributed to JS' salary.

\section{Conflict of interest disclosure}

445 The authors of this article declare that they have no financial conflict of interest with the content 446 of this article.

\section{Authors' contribution}

448 PG, EL and JS designed the study. AA, AAK, PFL, RP, GM, SA, AB, ED, BO, AMT, LMG and 449 PD collected the genetic samples and supplied curated databases. JD and PG did the lab work. 450 JS conducted data analyses. JS and PG drafted a first version of the manuscript. All co-authors participated in the writing of the manuscript and agreed with its last version. 


\section{References}

454 1. Lister AM, Stuart AJ. 2008 The impact of climate change on large mammal distribution and 
502

503

504

505

506

507

508

509

510

511

512

513

514

515

516

517

518

519

520

521

522

523

524

525

526

527

528

529

530

531

532

533

534

535

536

537

538

539

540

541

542

543

544

545

546

547

548

549

550

551

552

Natl. Acad. Sci. U. S. A. 105, 14319-14324.

22. Trantalidou K. 2011 From Mesolithic fishermen and bird hunters to Neolithic goat herders: the transformation of an island economy in the Aegean. Cave Cyclops Mesolith. Neolit. Netw. North. Aegean Greece 2, 53-150.

23. Brito C. 2012 Portuguese sealing and whaling activities as contributions to understand early northeast Atlantic environmental history of marine mammals. New Approaches Study Mar. Mamm. , 207-222.

24. Panou A, Jacobs J, Panos D. 1993 The endangered Mediterranean monk seal Monachus monachus in the lonian Sea, Greece. Biol. Conserv. 64, 129-140.

25. Borrell A, Cantos G, Aguilar A, Androukaki E, Dendrinos P. 2007 Concentrations and patterns of organochlorine pesticides and PCBs in Mediterranean monk seals (Monachus monachus) from Western Sahara and Greece. Sci. Total Environ. 381, 316-325.

26. Kovacs KM et al. 2012 Global threats to pinnipeds. Mar. Mammal Sci. 28, 414-436.

27. Pires R, Neves HC, Karamanlidis AA. 2008 The critically endangered Mediterranean monk seal Monachus monachus in the archipelago of Madeira: Priorities for conservation. Oryx 42, 278-285.

28. Silva MA, Brito C, Santos SV, Barreiros JP. 2009 Historic and recent occurrences of pinnipeds in the Archipelago of the Azores. Mammalia 73, 60-62.

29. Forcada J, Hammond PS, Aguilar A. 1999 Status of the Mediterranean monk seal Monachus monachus in the western Sahara and the implications of a mass mortality event. Mar. Ecol. Prog. Ser. 188, 249-261.

30. Stoffel MA et al. 2018 Demographic histories and genetic diversity across pinnipeds are shaped by human exploitation, ecology and life-history. Nat. Commun. 9, 1-12.

31. Benjamin J et al. 2017 Late Quaternary sea-level changes and early human societies in the central and eastern Mediterranean Basin: An interdisciplinary review. Quat. Int. 449, 29-57.

32. Thunell RC. 1979 Eastern Mediterranean Sea during the last glacial maximum; an 18,000years BP reconstruction. Quat. Res. 11, 353-372.

33. Mikolajewicz U. 2011 Modeling Mediterranean ocean climate of the last glacial maximum. Clim. Past 7, 161-180.

34. Colonese AC, Mannino MA, Mayer DB-Y, Fa DA, Finlayson JC, Lubell D, Stiner MC. 2011 Marine mollusc exploitation in Mediterranean prehistory: an overview. Quat. Int. 239, 86103.

35. Cunliffe B. 2017 On the Ocean: The Mediterranean and the Atlantic from prehistory to AD 1500. Oxford University Press.

36. Pastor T, Garza JC, Aguilar A, Tounta E, Androukaki E. 2007 Genetic diversity and differentiation between the two remaining populations of the critically endangered Mediterranean monk seal. Anim. Conserv. 10, 461-469.

37. Dayon J, Lecompte E, Aguilar A, de Larrinoa PF, Pires R, Gaubert P. 2020 Development and characterization of nineteen microsatellite loci for the endangered Mediterranean monk seal Monachus monachus. Mar. Biodivers. 50, 1-7.

38. Gaubert $\mathrm{P}$ et al. 2019 Insights from 180 years of mitochondrial variability in the endangered Mediterranean monk seal (Monachus monachus). Mar. Mammal Sci. 35, 1489-1511.

39. Rey-Iglesia A et al. 2021 Mitogenomics of the endangered Mediterranean monk seal (Monachus monachus) reveals dramatic loss of diversity and supports historical gene-flow between Atlantic and eastern Mediterranean populations. Zool. J. Linn. Soc. 191, 11471159.

40. Pastor T, Garza JC, Allen P, Amos W, Aguilar A. 2004 Low genetic variability in the highly endangered Mediterranean monk seal. J. Hered. 95, 291-300.

41. Karamanlidis AA, Skrbinšek T, Amato G, Dendrinos $P$, Gaughran S, Kasapidis $P$, Kopatz 
553

554

555

556

557

558

559

560

561

562

563

564

565

566

567

568

569

570

571

572

573

574

575

576

577

578

579

580

581

582

583

584

585

586

587

588

589

590

591

592

593

594

595

596

597

598

599

600

601

602

603
A, Stronen AV. 2021 Genetic and demographic history define a conservation strategy for earth's most endangered pinniped, the Mediterranean monk seal Monachus monachus. Sci. Rep. 11, 1-10.

42. Karamanlidis AA, Gaughran S, Aguilar A, Dendrinos P, Huber D, Pires R, Schultz J, Skrbinšek T, Amato G. 2016 Shaping species conservation strategies using mtDNA analysis: the case of the elusive Mediterranean monk seal (Monachus monachus). Biol. Conserv. 193, 71-79.

43. Hurlbert SH. 1971 The nonconcept of species diversity: a critique and alternative parameters. Ecology 52, 577-586.

44. Goudet J. 2005 Hierfstat, a package for R to compute and test hierarchical F-statistics. Mol. Ecol. Notes 5, 184-186.

45. Nei M. 1978 Estimation of average heterozygosity and genetic distance from a small number of individuals. Genetics 89, 583-590.

46. Jombart T. 2008 adegenet: a R package for the multivariate analysis of genetic markers. Bioinformatics 24, 1403-1405.

47. Nei M. 1973 Analysis of gene diversity in subdivided populations. Proc. Natl. Acad. Sci. U. S. A. 70, 3321-3323.

48. Tonkin-Hill G, Lees JA, Bentley SD, Frost SD, Corander J. 2019 Fast hierarchical Bayesian analysis of population structure. Nucleic Acids Res. 47, 5539-5549.

49. Wright S. 1943 Isolation by distance. Genetics 28, 114-138.

50. Slatkin M. 1993 Isolation by distance in equilibrium and non-equilibrium populations. Evolution 47, 264-279.

51. Mantel N. 1967 The detection of disease clustering and a generalized regression approach. Cancer Res. 27, 209-220.

52. Cayuela H, Boualit L, Laporte M, Prunier JG, Preiss F, Laurent A, Foletti F, Clobert J, Jacob G. 2019 Kin-dependent dispersal influences relatedness and genetic structuring in a lek system. Oecologia 191, 97-112.

53. Salmona $J$ et al. $2021 \mathrm{How}$ ancient forest fragmentation and riparian connectivity generate high levels of genetic diversity in a micro-endemic Malagasy tree. BioRxiv 20201125394544 Ver 4 Peer-Rev. Recomm. Peer Community Evol. Biol. (doi:https://doi.org/10.1101/2020.11.25.394544)

54. Oden NL, Sokal RR. 1986 Directional autocorrelation: an extension of spatial correlograms to two dimensions. Syst. Zool. 35, 608-617.

55. Sokal RR. 1986 Spatial data analysis and historical processes. Data Anal. Inform. IV , 2943.

56. Nei M, Tajima F. 1981 DNA polymorphism detectable by restriction endonucleases. Genetics 97, 145-163.

57. Nei M. 1987 Molecular Evolutionary Genetics. Columbia University Press.

58. Paradis E. 2010 pegas: an R package for population genetics with an integrated-modular approach. Bioinformatics 26, 419-420.

59. Beaumont MA. 2019 Approximate Bayesian computation. Annu. Rev. Stat. Its Appl. 6, 379-403.

60. Wegmann D, Leuenberger C, Neuenschwander S, Excoffier L. 2010 ABCtoolbox: a versatile toolkit for approximate Bayesian computations. BMC Bioinformatics 11, 1-7.

61. Csilléry K, François O, Blum MG. 2012 abc: an R package for approximate Bayesian computation (ABC). Methods Ecol. Evol. 3, 475-479.

62. Nunes MA, Prangle D. 2015 abctools: an R package for tuning approximate Bayesian computation analyses. $R$ J. 7, 189-205.

63. Cornuet JM, Luikart G. 1996 Description and power analysis of two tests for detecting recent population bottlenecks from allele frequency data. Genetics 144, 2001-2014.

64. Garza JC, Williamson EG. 2001 Detection of reduction in population size using data from 
604

605

606

607

608

609

610

611

612

613

614

615

616

617

618

619

620

621

622

623

624

625

626

627

628

629

630

631

632

633

634

635

636

637

638

639

640

641

642

643

644

645

646

647

648

649

650

651

652

653

654 microsatellite loci. Mol. Ecol. 10, 305-318.

65. Slatkin M, Racimo F. 2016 Ancient DNA and human history. Proc. Natl. Acad. Sci. U. S. A. 113, 6380-6387.

66. Boutiba Z, Squabria B, Robineau D. 1988 Etat actuel de la population du phoque-moine (Monachus monachus) sur le littoral ouest algérien (région d'Oran). Mammalia 52, 549556.

67. Bundone L, Panou A, Molinaroli E. 2019 On sightings of (vagrant?) monk seals, Monachus monachus, in the Mediterranean Basin and their importance for the conservation of the species. Aquat. Conserv. Mar. Freshw. Ecosyst. 29, 554-563.

68. Kiraç C, Savaş Y. 1996 Status of the monk seal (Monachus monachus) in the neighbourhood of Ereğli, Black Sea coast of Turkey. Zool. Middle East 12, 5-12.

69. Kalkan E, Karhan SÜ, Bilgin R, Hemond EM. 2016 The Turkish straits system as a phylogeographic boundary-a literature review. Sea Marmara , 550-69.

70. Tonay AM et al. 2017 Is there a distinct harbor porpoise subpopulation in the Marmara Sea? Mitochondrial DNA Part A 28, 558-564.

71. Zulliger DE, Tanner S, Ruch M, Ribi G. 2009 Genetic structure of the high dispersal Atlanto-Mediterranean sea star Astropecten aranciacus revealed by mitochondrial DNA sequences and microsatellite loci. Mar. Biol. 156, 597-610.

72. Gaspari S, Scheinin A, Holcer D, Fortuna C, Natali C, Genov T, Frantzis A, Chelazzi G, Moura AE. 2015 Drivers of population structure of the bottlenose dolphin (Tursiops truncatus) in the Eastern Mediterranean Sea. Evol. Biol. 42, 177-190.

73. Schultz JK, Baker JD, Toonen RJ, Harting AL, Bowen BW. 2011 Range-wide genetic connectivity of the Hawaiian monk seal and implications for translocation. Conserv. Biol. 25, 124-132.

74. Toonen RJ et al. 2011 Defining boundaries for ecosystem-based management: a multispecies case study of marine connectivity across the Hawaiian Archipelago. J. Mar. Biol. 2011, 460173.

75. Valtonen M, Palo JU, Aspi J, Ruokonen M, Kunnasranta M, Nyman T. 2014 Causes and consequences of fine-scale population structure in a critically endangered freshwater seal. BMC Ecol. 14, 1-15.

76. Weber D, Stewart BS, Garza JC, Lehman N. 2000 An empirical genetic assessment of the severity of the northern elephant seal population bottleneck. Curr. Biol. 10, 1287-1290.

77. Cammen KM et al. 2018 Genetic diversity from pre-bottleneck to recovery in two sympatric pinniped species in the Northwest Atlantic. Conserv. Genet. 19, 555-569.

78. Bocquet-Appel J-P. 2008 Explaining the Neolithic demographic transition. In The Neolithic demographic transition and its consequences, pp. 35-55. Springer.

79. Zilhão J. 2014 Early prehistoric navigation in the Western Mediterranean: Implications for the Neolithic transition in Iberia and the Maghreb. Eurasian Prehistory Isl. Archaeol. Orig. Seafar. East. Mediterr. 11, 185-200.

80. Simmons AH. 2016 Stone Age sailors: Paleolithic seafaring in the Mediterranean. Routledge.

81. Zeder MA. 2008 Domestication and early agriculture in the Mediterranean Basin: Origins, diffusion, and impact. Proc. Natl. Acad. Sci. U. S. A. 105, 11597-11604.

82. Phoca-Cosmetatou N. 2011 The first Mediterranean islanders: initial occupation and survival strategies. University of Oxford School of Archaeology.

83. Plinius Secundus G. 77 ADNaturalis Historiae. 1940th-The Loeb Classical Library edn. Cambridge, Massachusetts, : Harvard University Press.

84. Oppianus Corycius. 169 ADHalieutica. Harvard University Press.

85. Scullard HH. 2010 From the Gracchi to Nero: a history of Rome 133 BC to AD 68. Routledge.

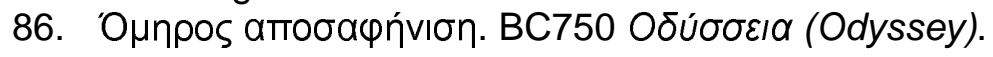




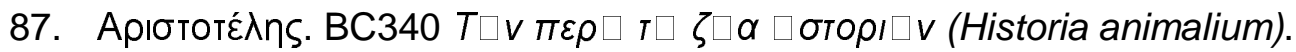

88. McClenachan L, Cooper AB. 2008 Extinction rate, historical population structure and ecological role of the Caribbean monk seal. Proc. R. Soc. B Biol. Sci. 275, 1351-1358.

89. Trakadas A. 2006 'Exhausted by Fishermen's Nets' Roman Sea Fisheries and their Management. J. Mediterr. Stud. 16, 259-272.

90. Kidd E. 2012 "Beast-Hunts" in Roman Amphitheaters: The Impact of the Venationes on Animal Populations in the Ancient Roman World. Eagle Feather 9.

91. Bernal-Casasola D. 2018 Whale Hunting in the Strait of Gibraltar during the Roman Period? SAA Archaeol. Rec.

92. Steele TE, Álvarez-Fernández E. 2011 Initial investigations into the exploitation of coastal resources in North Africa during the Late Pleistocene at Grotte des Contrebandiers, Morocco. In Trekking the Shore, pp. 383-403. Springer.

93. Morales-Pérez JV, Ripoll MP, Pardo JJ, Álvarez-Fernández E, González AM, Tortosa JA. 2019 Mediterranean monk seal hunting in the regional Epipalaeolithic of Southern Iberia. A study of the Nerja Cave site (Málaga, Spain). Quat. Int. 515, 80-91.

94. Bernal-Casasola D, Expósito JA, Díaz JJ. 2018 The Baelo Claudia Paradigm: The Exploitation of Marine Resources in Roman Cetariae. J. Marit. Archaeol. 13, 329-351.

95. Mo G, Bazairi H, Bayed A, Agnesi S. 2011 Survey on Mediterranean Monk Seal (Monachus monachus) Sightings in Mediterranean Morocco. Aquat. Mamm. 37.

96. Reilly SB. 2005 Report of the scientific research program under the International Dolphin Conservation Program Act.

97. Batson WG, Gordon IJ, Fletcher DB, Manning AD. 2015 Translocation tactics: a framework to support the IUCN Guidelines for wildlife translocations and improve the quality of applied methods. J. Appl. Ecol. 52, 1598-1607.

98. Pacioni C, Wayne AF, Page M. 2019 Guidelines for genetic management in mammal translocation programs. Biol. Conserv. 237, 105-113.

99. Lenormand T. 2002 Gene flow and the limits to natural selection. Trends Ecol. Evol. 17, 183-189.

100. Leimu R, Fischer M. 2008 A meta-analysis of local adaptation in plants. PloS One 3, e4010.

101. Edmands S. 2007 Between a rock and a hard place: evaluating the relative risks of inbreeding and outbreeding for conservation and management. Mol. Ecol. 16, 463-475.

102. Bell DA, Robinson ZL, Funk WC, Fitzpatrick SW, Allendorf FW, Tallmon DA, Whiteley AR. 2019 The exciting potential and remaining uncertainties of genetic rescue. Trends Ecol. Evol. 34, 1070-1079. 